\title{
Assessment of Striatal Extracellular Dopamine and Dopamine Metabolites by Microdialysis in Haloperidol-Treated Rats Exhibiting Oral Dyskinesia
}

Ronald E. See, Ph.D.

Ints that had received continuous, chronic haloperidol OHAL) for 32 weeks were monitored for changes in oral Hetents as determined by Fast Fourier analysis of jaw arments recorded with a computerized video analysis sstem. Beginning at 24 weeks of administration, HL-treated animals exhibited a pattern of significant meases in oral movement activity in the 1 to $3 \mathrm{~Hz}$ mene and decreases in the 5 to $8 \mathrm{~Hz}$ range when ampared to control animals. The release and metabolism dopamine $(D A)$ in the striatum of these animals was assessed using intracranial microdialysis during 32 of HAL administration and 3 days after whdraival of HAL. Basal extracellular concentrations of DA metabolites, 3,4-dihydroxyphenylacetic acid and movarillic acid were significantly increased in the
HAL-treated rats during continuous $H A L$ administration. Three days after withdrawal from $H A L$, no difference was seen in basal extracellular concentrations of any of the analytes. No difference in the magnitude of $D A$ release was seen between groups following local application of amphetamine (10 $\mu \mathrm{M})$ through the dialysis probe during or after chronic $H A L$ administration. These results confirm previous findings that long-term HAL administration produces increased $D A$ turnover during HAL administration, but that this increase does not persist following HAL withdrawal. The increased striatal DA turnover seen during chronic HAL administration may have relevance to the development of late-onset neuroleptic-induced dyskinesia in rats.

[Neuropsychopharmacology 9:101-109, 1993] or wORDs: Haloperidol; Oral movement; Dopamine; Mrrodialysis; Striatum; Tardive dyskinesia

Oronic neuroleptic administration during the treatant of schizophrenia and other disorders can lead to te development of tardive dyskinesia (TD), a latemoet movement disorder that usually exhibits as chomovements of the orofacial region (Marsden and mner 1980; Casey 1987). A number of approaches

from the Department of Psychology, Washington State Univer-7. Pullman, Washington.

iddress correspondence to: Dr. Ronald E. See, Department of huchology, Washington State University, Pullman, Washington, nivet 420 .

Rreved September 25, 1992; revised January 29, 1993; accepted uxth 11. 1993. have been taken to develop an animal model of TD in both nonhuman primates (Gunne and Barany 1976) and rodents (Waddington 1990). The most successful approaches in this regard have utilized several months to years of neuroleptic administration, based on the fact that TD usually does not develop prior to such prolonged drug exposure. Following long-term administration of haloperidol (HAL) or fluphenazine, it has been found that rats develop unique alterations in oral movements that are not seen early in treatment and that persist following withdrawal of the neuroleptic (See et al. 1988; Ellison and See 1989). These movement patterns are qualitatively similar in some regards to dyskinesias characterized in human TD patients; specifically, fast Fourier transformation (FFT) analysis of jaw movements shows an increase in spectral 
power predominantly in the 1 to $3 \mathrm{HZ}$ range in rats (Ellison and See 1989; See and Ellison 1990a). Studies of human TD patients have consistently shown that dyskinesia is also located within the lower (less than $4 \mathrm{~Hz}$ ) frequency range (Nishikawa et al. 1985; Caligiuri et al. 1989; Wirshing et al. 1989; Lohr and Caligiuri 1992). Finally, administration of the atypical neuroleptic, clozapine, does not produce this pattern of altered oral movement activity in the rat model of TD (See and Ellison 1990b).

This correlational animal model of TD has allowed for an exploration of the possible underlying pathophysiology that results following prolonged neuroleptic exposure. Using intracranial microdialysis techniques, we have recently found that chronic treatment (32 weeks) with HAL increases basal extracellular concentrations of the dopamine (DA) metabolites, 3,4dihydroxyphenylacetic acid (DOPAC) and homovanillic acid (HVA), in the striatum of rats (See 1991). This effect is also apparent following 8-month administration of intramuscular fluphenazine decanoate and HAL decanoate (See et al. 1992). These increases in DA metabolism are not observed during and after 3 weeks of HAL administration (See and Murray 1992), and they are not apparent in the nucleus accumbens of chronic neuroleptic-treated animals (See et al. 1992).

To further characterize changes in DA function produced by chronic HAL treatment in rats and their possible relation to late-onset motor side effects, the present study focused on changes in oral movement patterns during prolonged HAL administration (32 weeks) and extracellular striatal DA function as measured by intracranial microdialysis. To assess the effects of persisting HAL, dialysis collection was performed both during continuous HAL administration and 3 days after withdrawal from HAL administration.

\section{MATERIALS AND METHODS}

\section{Drug Administration}

Female Sprague-Dawley rats were single housed and maintained on a 12-hour light/dark cycle with continuous access to food and water. Animals were divided into chronic HAL and control (CON) groups $(n=9$ each). Body weights for these groups did not significantly differ at the beginning or end of the chronic administration period. Initial body weights in grams were: $324 \pm 5$ (HAL) and $315 \pm 9(\mathrm{CON})$; final body weights: $354 \pm 10$ (HAL) and $371 \pm 17(\mathrm{CON})$. Chronic subcutaneous HAL was administered via silastic reservoirs containing $100 \mathrm{mg}$ HAL base (Sigma, St. Louis, MO). Construction details for these silastic reservoirs are described in detail elsewhere (Ellison and See 1991). The release rate of these implants is ap. proximately $0.23 \mathrm{mg} /$ day, thus giving a dose of 0.7 $\mathrm{mg} / \mathrm{kg} /$ day for a 333-g rat. Animals in the CON group were subcutaneously implanted with an empty silastic reservoir. Fresh reservoirs were implanted after 16 weeks to ensure stable HAL administration.

\section{Oral Movement Recording}

Rats were habituated to placement in plexiglas tubes (6.2- $\mathrm{cm}$ diameter, $20.0-\mathrm{cm}$ length) resting inside a soundproof chamber. Before the onset of testing, all rats were habituated to the tube in four separate 5-minute sessions over a 2-week time period. Animals habituated well to the test apparatus and showed minj. mal struggling during the brief 5-minute session. Rats were placed in the tube 1 to 2 minutes prior to the beginning of a 5-minute data collection session. At the end of the tube was a 3.3-cm-diameter hole through which the rat's head protruded. Prior to being placed in the tube, small spots were painted on the upper and lower jaws of the rat using an ultraviolet (UV)-sensitive dye. A video camera with a UV filter was positioned in front of the rat and connected to a computer equipped with a movement detection circuit (MM board; Biotronics Design, Tarzana, CA), which monitored only the two painted spots. This circuit calculated the distance between the upper and lower spots at a rate of 60 times per second. Oral activity was thus recorded as individual openings or closings of the jaws or "computer scored movelets" (CSMs). A computer program analyzed the data for each file and classifed each CSM according to amplitude, as determined by the number of TV rasters covered by the CSM. The distribution of CSM amplitudes was divided into five categories according to the number of rasters covered: 2 , 3,4 to 5,6 to 9 , equal to or greater than 10 . The corre sponding distances in millimeters were $0.6,0.9,1.2$ to 1.5, 1.8 to 2.7, equal to or greater than 3.0. The slope of each CSM (amplitude/duration) was determined as well. The data from the computerized jaw movement apparatus were also subjected to FFT as previously de scribed (Ellison and See 1989).

Animals were tested for oral movements priorto initiation of HAL administration (week 0 ) and once ev. ery 8 weeks during the course of the study (weeks 8 , 16,24 , and 32). Testing at week 32 was conducted! days after surgical implant of the guide cannulae prior to the microdialysis experiment (see below). In addi tion, at week 28, oral movements were assessed 30 minutes following intraperitoneal injection of the $\mathrm{DA}$ $\mathrm{D}_{1}$ receptor antagonist SCH-23390 $(0.25 \mathrm{mg} / \mathrm{kg})$ a distilled-water vehicle. This dose was selected based on previous data obtained with this computerized testing system that demonstrated a significant de crease in oral movements at this dose (Levin et al 
1999). Half of the animals were initially tested with SCH-23390 and half with vehicle. Three days later, nimals were tested with the opposite treatment.

\section{Mioodialysis}

Atter 31 weeks of continuous HAL administration, ats were anesthetized with Equithesin $(0.3 \mathrm{ml} / 100 \mathrm{~g})$ nd bilateral guide cannulae (20-gauge) were implanted into the striatum (from bregma: A, +0.2; L, $-3.5 ; \mathrm{V},-5.0$ ) according to the atlas of Paxinos and Watson (1986). Dialysis probes were constructed with aysis membrane (250- $\mu \mathrm{m}$ outer membrane) based mpreviously described methods (Robinson and Whihaw 1988). A 3-mm length of dialysis membrane was aposed at the tip of the probe which extended $3 \mathrm{~mm}$ yond the guide cannula. In vitro recoveries of DA, DOPAC, HVA, and 5-hydroxyindoleacetic acid (5HIAA) at $37^{\circ} \mathrm{C}$ consistently ranged from $10 \%$ to $15 \%$. One week after surgery, dialysis probes were unilaterdy inserted and left in place for 16 to 18 hours prior b beginning sample collection. Initial probe insertion wos randomized so that half of the animals had the st probe placement in the left striatum and half in the right striatum. The next day, perfusion with dialyis buffer began 120 minutes prior to the collection of beseline samples. Probes were perfused $(2 \mu \mathrm{l} / \mathrm{min})$ with dialysis buffer $\left(\mathrm{NaCl}, 147 \mathrm{mM} ; \mathrm{CaCl}_{2}, 1.8 \mathrm{mM}\right.$; Ka, $5 \mathrm{mM} ; \mathrm{MgCl}_{2}, 1.2 \mathrm{mM}$; pH 7.4). Perfusate samphes were collected in microcentrifuge tubes $(0.5 \mathrm{ml})$ montaining $20 \mu \mathrm{l}$ of the mobile phase $(0.1 \mathrm{M}$ citric acid, $0.75 \mathrm{mM} \mathrm{Na} 2 \mathrm{HPO}_{4}, 1.0 \mathrm{mM}$ heptane sulphonic acid, Q. $\mathrm{mM}$ ethylenediaminetetraacetic acid, $14 \%$ metha$\boldsymbol{w}, \mathrm{pH}=4.2$ ) with 2 pmol dihydroxybenzylamine as the intemal standard. Three consecutive samples colated at 20-minute intervals for 1 hour provided a weline prior to a 1-hour infusion through the dialysis pobe of $10 \mu \mathrm{M} d$-amphetamine sulfate (AMP) disstved in dialysis buffer. Samples were collected durAMP infusion and for 60 minutes following termietion of AMP infusion. Animals were removed from the dialysis chambers, HAL treatment was terminated 7 removal of the silastic reservoirs, and the animals numed to their home cage. The animals were then tested 3 days later using the same procedure but with the dialysis probe inserted into the side con- nateral to the initial probe. Rats were killed after the mal probe removal by rapid decapitation. Brain tissue wo dissected over ice and coronal sections that indoded the site of cannula implantation were sectioned and stained with cresyl violet for verification of probe perement. Additional tissue was saved and stored for ther neurochemical assays. Each dialysis sample montaining $20 \mu \mathrm{l}$ of mobile phase and $40 \mu \mathrm{l}$ of perwaste) was directly injected by an autosampler into thehigh-performance liquid chromatography system.
Separation of DA, DOPAC, HVA, and 5-HIAA was accomplished on a reversed-phase column (Biophase ODS $5 \mu, 25 \mathrm{~cm}$; Bioanalytical Systems, West Lafayette, IN) and a coulometric electrochemical detection system (model 5100A; ESA, Inc., Bedford, MA) for detecting analytes (guard electrode $=+0.4 \mathrm{~V}$, oxidation electrode $=+0.35 \mathrm{~V}$, and reduction electrode $=$ $-0.25 \mathrm{~V})$.

\section{Statistical Analysis}

The Kruskal-Wallis one-way analysis of variance (ANOVA) was used for measures of CSM amplitudes and CSM slopes. For FFT, the absolute energy at a particular frequency was converted to the percent of total energy across all frequency bands. Repeated-measures ANOVA were used for statistical analysis of FFT data. If the value of $F$ was significant at $p<.05$, specific post-hoc comparisons were made with the NewmanKeuls test for individual comparisons. Basal extracellular concentrations of dialysates were analyzed by ANOVA. For analysis of responses to AMP infusion, data were converted to percentage of preinfusion baseline with repeated-measures ANOVAs and posthoc testing for individual group comparisons (Newman-Keuls test). Significant differences were defined at $p<.05$ and $p<.01$.

\section{RESULTS}

\section{Oral Movement Analysis}

Computerized analysis of oral movements demonstrated no significant differences between groups over time for total number of CSMs of medium-sized amplitudes (Amplitude 6 to 9; Fig. 1, top left) or for largesized amplitudes (Amplitudes equal to or greater than 10; Fig. 1, bottom left). Analysis of slope values (amplitude/duration) showed significant differences only at week 24, when HAL-treated animals were significantly lower than CON animals for Amplitudes 6 to 9 (Fig. 1, top right) and Amplitudes equal to or greater than 10 (Fig. 1, bottom right).

In contrast to the lack of significant differences in total number of CSMs over time, FFT analysis showed an increasing trend for a shift in the percentage of energy at individual frequencies in the HAL group. Specifically, relative increases in spectral energy were seen at low frequencies and decreases were seen in the midrange frequencies in the HAL group relative to the CON group (Fig. 2). No significant difference was seen at weeks 0,8 , and 16 , although this trend was apparent at week 16 . By week 24, HAL-treated animals were significantly increased at $1 \mathrm{~Hz}(p<.05)$ and significantly decreased at $5 \mathrm{~Hz}(p<.05)$ and $6 \mathrm{~Hz}(p<$ $.01)$. At week 32 in tests conducted 4 days after 

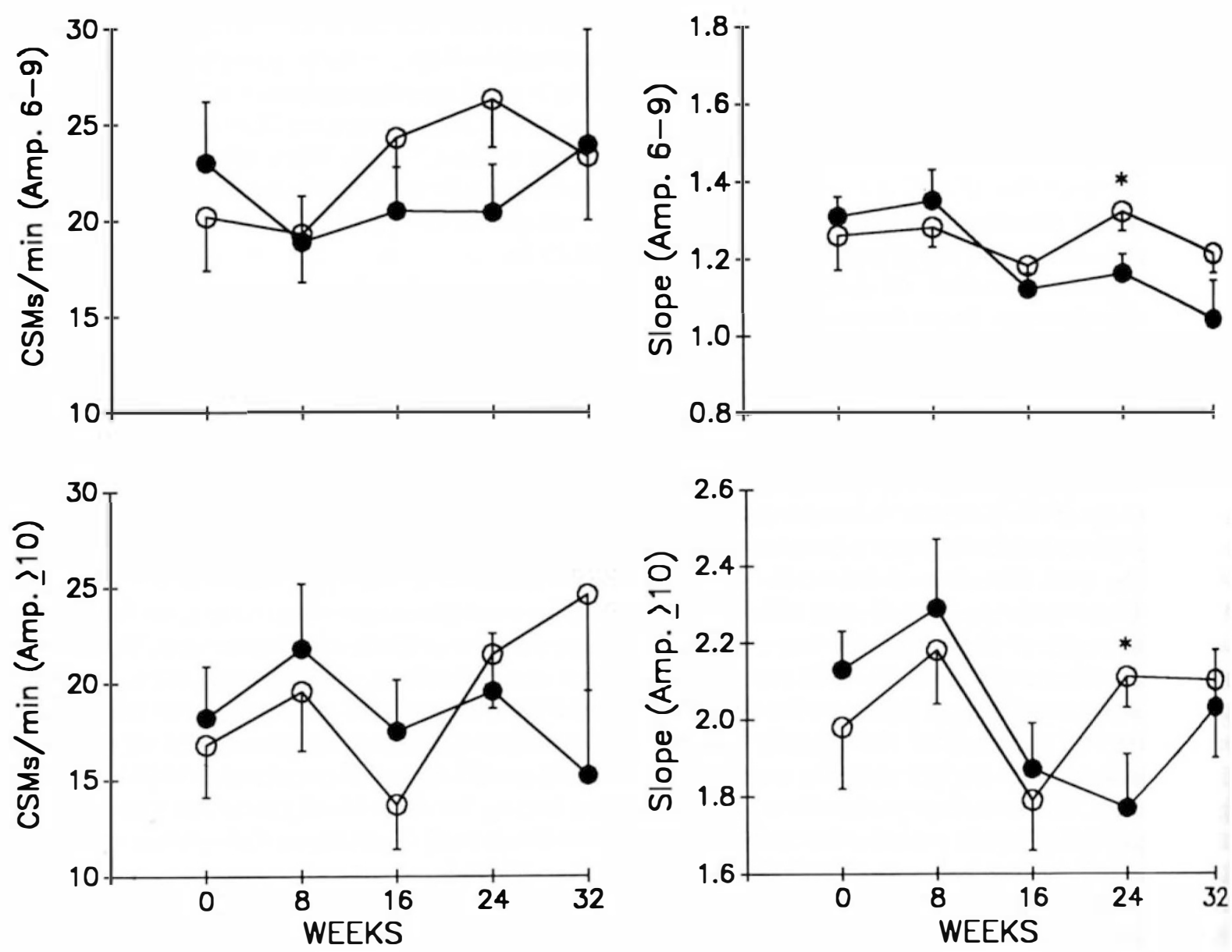

Figure 1. Frequency and slope means \pm SEM of CSMs of amplitudes 6 to 9 and equal to or greater than 10 during chronic HAL administration. Filled circles, HAL; open circles, CON. Top left: Frequency of CSMs per min for amplitudes 6 to 9. Bottom left: Frequency of CSMs per min for amplitudes equal to or greater than 10. Top right: Average slopes for amplitudes 6 to 9. Bottom right: Average slopes for amplitudes equal to or greater than 10. "Weeks" indicate test sessions during chronix HAL administration. (Significantly different from control, ${ }^{\star} p<.05$.)

bilateral cannulae implantation, HAL-treated rats were significantly increased at $3 \mathrm{~Hz}(p<.05)$ and significantly decreased at 6,7 , and $8 \mathrm{~Hz}(p<.05)$. This shift was not due to changes in the overall amount of absolute energy, because there were no significant differences between groups for total energy at any of the test sessions.

Acute injection of SCH-23390 at week 28 produced a significant decrease in CSMs in the CON group compared to vehicle injection $(p<.05$; Fig. 3$)$. The HAL group showed a lower number of CSMs when compared to $\mathrm{CON}$ animals following vehicle injection, although this effect was not significantly different. There was also no significant effect of SCH-23390 injection on total number of CSMs in the HAL group. Fast Fourier transformation analysis showed a pattern of increased energy at $2 \mathrm{~Hz}$ in the HAL group after vehicle injection $(p<.05)$ and decreases at higher frequencies (Fig. 4). Injection of SCH-23390 attenuated this pattern in the HAL group by reducing the increase at $2 \mathrm{~Hz}$ and increasing the percentage of energy in the midrange frequencies. Injection of $\mathrm{SCH}-23390$ did not produce any significant differences in the spectral energy pattern in the CON group when compared to vehicle in jection.

\section{Dialysis}

Figure 5 shows basal extracellular concentrations $d$ DA, DOPAC, HVA, and 5-HIAA during the periodd continuous HAL administration (top) and 3 days af. ter withdrawal (bottom). There was a significant over all difference between groups for DOPAC $(F[3,27]=$ $4.09, p<.05)$ and HVA $(F[3,27]=3.62, p<.05)$ but not for DA $(F[3,27]=1.39$, NS) or 5-HIAA $(F[3,27]=$ 0.49 , NS). Group comparisons (Newman-Keuls test) showed that DOPAC was significantly higher in the HAL animals during administration when companed to CON animals $(p<.05)$ and when compared to values in the HAL group following drug withdrawd 


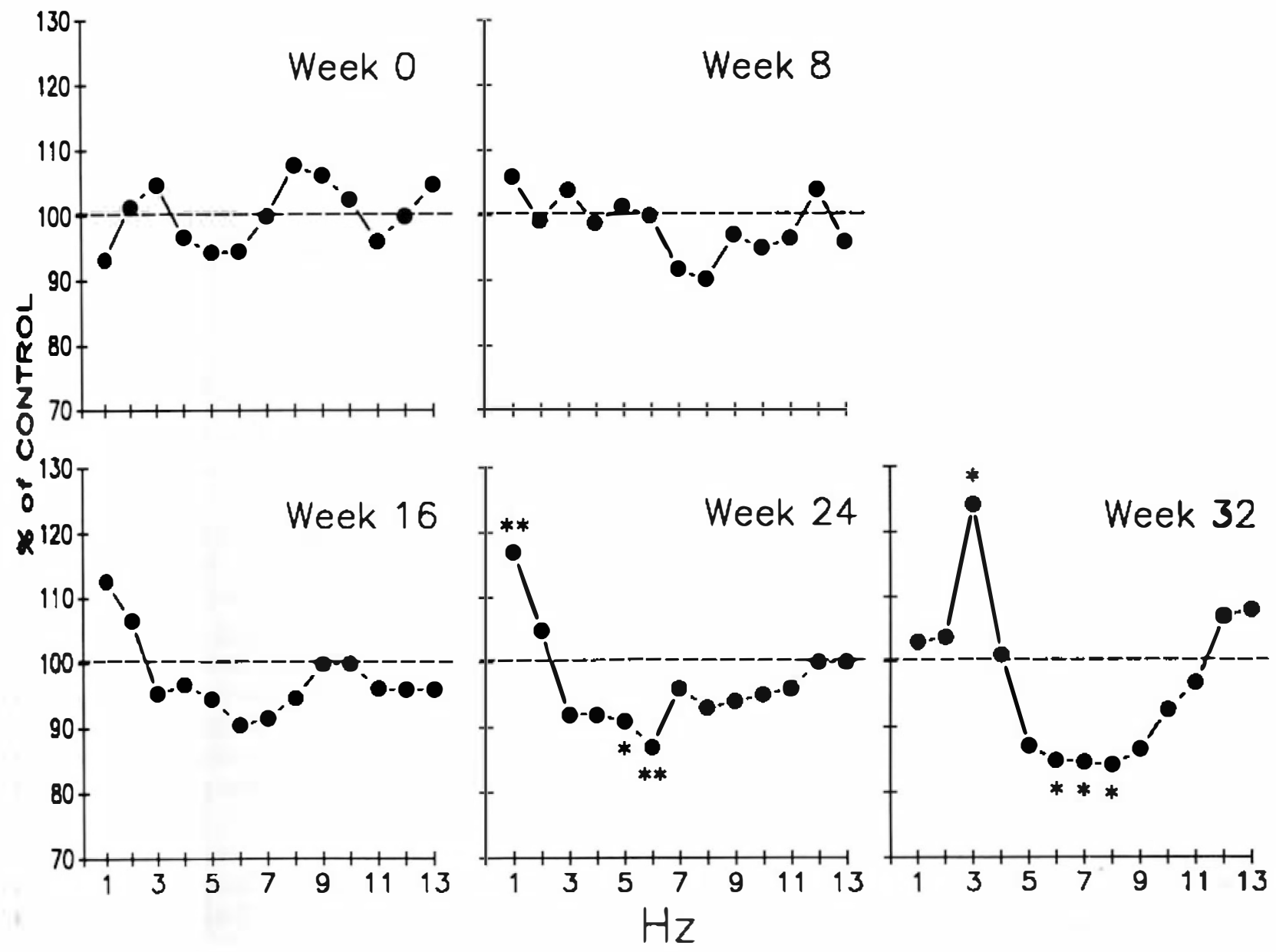

Fiue 2. Fast Fourier spectrum for CSMs during chronic HAL administration. Values are expressed as mean percent of matrol. (" $p<.05$ and ${ }^{\star \star} p<.01$, Newman-Keuls test.)

b .05). Levels of HVA showed marginally significant efferences between HAL and CON during HAL treatment $(p<.10$, Newman-Keuls test); however, there mas a significant difference in HVA concentrations be-

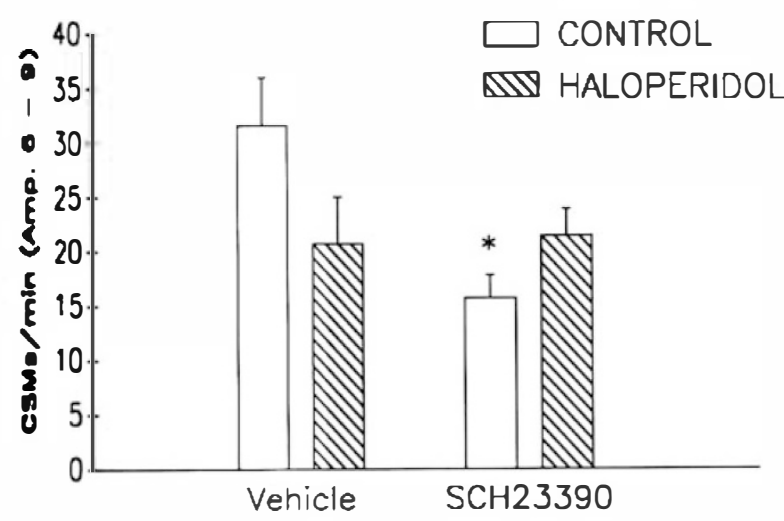

Fyure 3. Effects of intraperitoneal injections of vehicle or SCH-23390 (0.25 mg/kg) on CSMs per min (means \pm SEM) d amplitude 6 to 9 . Testing for oral activity was conducted D minutes after injection. ( ${ }^{*} p<.05$ compared to control + wicle, Mann-Whitney U-test.) tween the HAL group during administration and 3 days after HAL withdrawal $(p<.05)$.

Infusion of AMP through the dialysis probe produced highly significant increases $(p<.01)$ in extracellular DA concentrations in both groups throughout the period of infusion at week 32 during HAL (Fig. 6, top) and 3 days after HAL withdrawal (Fig. 6, bottom). Dopamine concentrations showed a rapid return to baseline following cessation of AMP infusion. There were no significant differences between HAL and $\mathrm{CON}$ at any time point for DA levels. Concentrations of DOPAC, HVA, and 5-HIAA were transiently increased just after beginning AMP infusion (data not shown); but again, there were no significant differences between HAL and CON groups either during or after chronic administration.

\section{DISCUSSION}

The present findings replicate a number of previous studies that have demonstrated a late-onset pattern of 


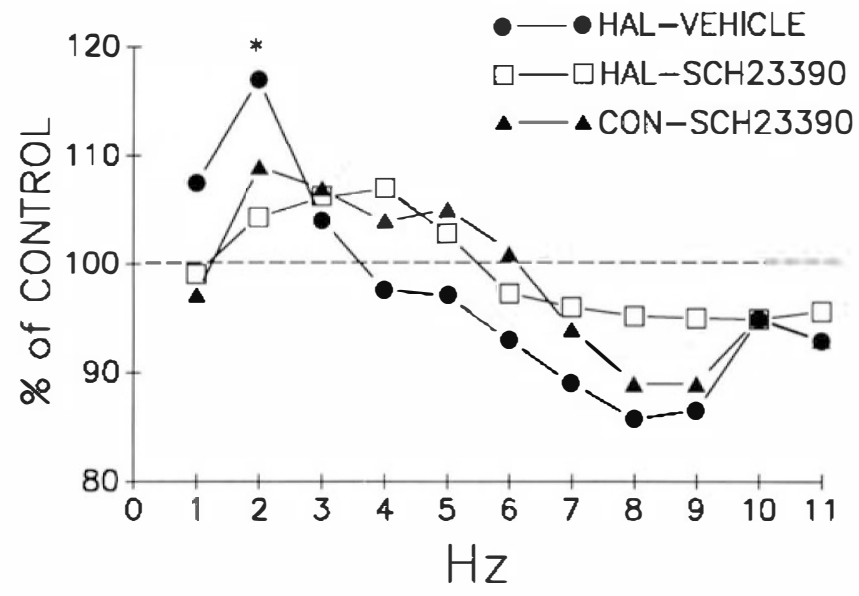

Figure 4. Fast Fourier frequency distribution for CSMs as percent of control-vehicle 30 minutes after intraperitoneal administration of vehicle or SCH-23390 (0.25 mg/kg). ( ${ }^{*} p<$ .05, Newman-Keuls test.)

changes in oral activity in rats that have been administered HAL. Specifically, a gradual increase in energy at the lower frequency range ( 1 to $3 \mathrm{~Hz}$ ) with a decrease in the midfrequency range $(5$ to $8 \mathrm{~Hz}$ ) emerged after 16 to 24 weeks of treatment. Although the animals in the present study were not studied for a long withdrawal period, we have previously demonstrated that this pattern persists following drug withdrawal (Ellison and See 1989; See and Ellison 1990a). The finding that TD patients consistently demonstrate

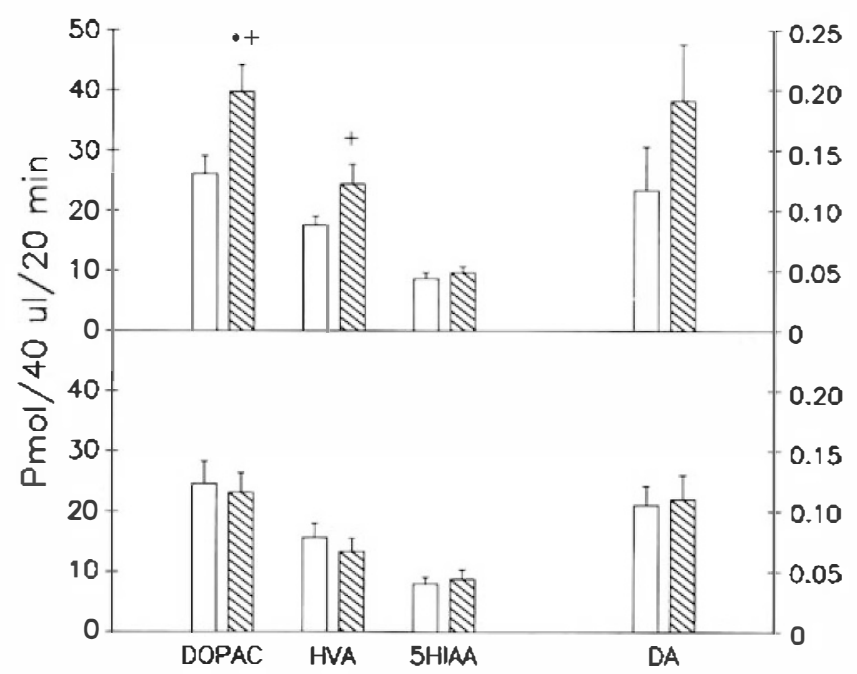

Figure 5. Basal extracellular concentrations of DA, DOPAC, HVA, and 5-HIAA at week 32 of HAL administration (top) and 3 days after withdrawal (bottom). Control, open bars; $\mathrm{HAL}$, hatched bars. Data are means \pm SEM expressed as $\mathrm{pmol} / 40 \mu \mathrm{l}$ dialysate $/ 20 \mathrm{~min}$. Scale for the metabolite levels is represented on the left, while the scale for DA is represented on the right. (Significantly different from control, ${ }^{\star} p<.05$; significantly different from withdrawal concentration, $+p<.05$.)

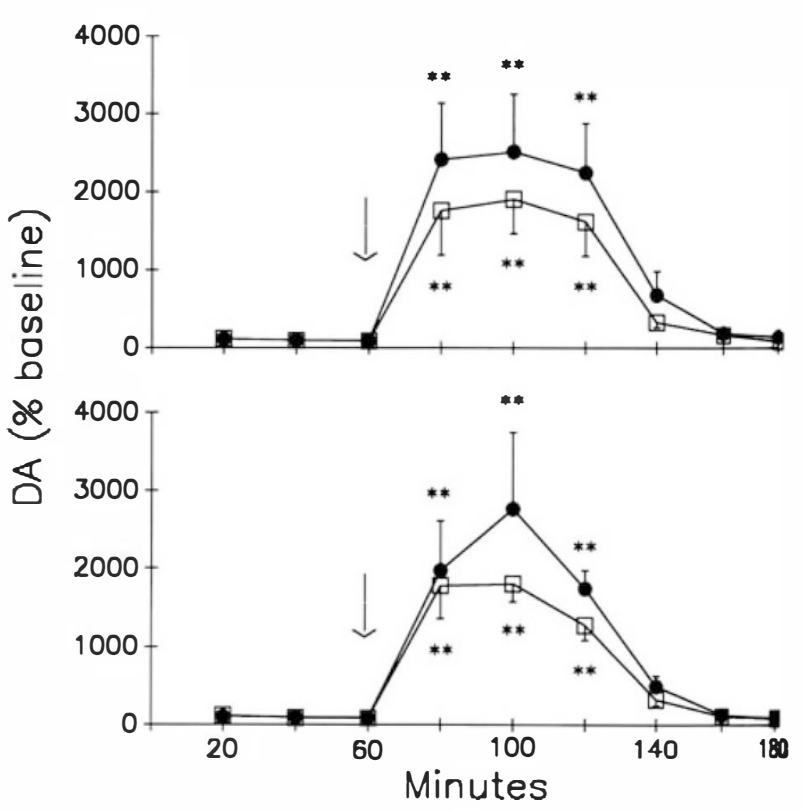

Figure 6. Effects of amphetamine $(10 \mu \mathrm{M})$ on striatal ex. tracellular levels of DA at 32 weeks of HAL administration (top) and 3 days after withdrawal (bottom): HAL (- ) and $\mathrm{CON}(\square-\square)$. Data (means \pm SEM) are expressed as a percent of the mean of 3 baseline values obtained prior to 1 hour of amphetamine infusion (arrow). $\left({ }^{* \star} p<.01\right.$, NewmanKeuls test.)

orofacial dyskinesia in the 1 to $3 \mathrm{~Hz}$ range (Lohr and Caligiuiri 1992) strengthens the contention that ord movement changes in rats following long-term nelroleptic administration represents an animal analogue of TD. Interestingly, at week 32 , there was a shift in the pattern such that HAL-treated rats were signifcantly increased at $3 \mathrm{~Hz}$. This effect may be related to the effects of cannulae implantation on the overlying cortical tissue, because direct lesioning of cortex has been previously shown to exacerbate vacuous ord movements in HAL-treated rats (Glassman and Glass. man 1980; Gunne et al. 1982).

With the advent of DA receptor subtype-specifr drugs, there has been much interest in the role of $D A$ receptor subtypes in the pathophysiology of TD (Cerlach and Casey 1988). In rats, it has been reported that DA $D_{1}$ receptor agonists such as SKF-38393 can exacerbate oral movements in rats, whereas $D_{2}$ agonist such as quinpirole decrease oral movements (Rosengarten et al. 1983; Johansson et al. 1987; Ellison et al 1988). Utilizing the computerized video analysis sys tem described here, it has been found that SKF-383\% intensifies the $1-$ to $3-\mathrm{Hz}$ peak energy pattern in chronic HAL-treated rats (Ellison and Liminga 1991). Utilizing a dose of SCH-23390 that has been previoust? shown to suppress oral movements in drug-naive animals (Levin et al. 1989), the present study found that the total number of CSMs decreased in the CON animals but did not decrease in HAL-treated rats. This 
dfect may be due to the higher number of CSMs seen ther vehicle injection in the $\mathrm{CON}$ group, thus giving a higher baseline in this group. However, there was in SCH-23390-induced attenuation of the spectral mergy pattern in the HAL-treated animals as demontrated by FFT. This would appear to support the poswility that acute $\mathrm{D}_{1}$ receptor antagonist administraion may reduce TD-like oral movements. Previous sodies in which SCH-23390 was administered have do reported a suppression of oral movements in Ruroleptic-treated rats (Stoessl et al. 1989) and primates exhibiting orofacial dyskinesia (Rupniak et al. 1990).

Previous studies have shown that DA receptor linding may vary during the estrous cycle of female ats (Di Paolo et al. 1988; Levesque et al. 1989). Thus, is possible that hormonal fluctuations linked to the strous cycle may affect dopaminergic function and motor activity in females. Although the effects noted in the present study follow a predicted temporal patmor fore-onset neuroleptic-induced changes, conderation must be given when comparing results from female rats with male rats. The present study utired female rather than male rats based on several facm. A number of previous experiments (See et al. 198 ; See and Ellison 1990a, 1990b; See 1991) have utibed female rats in assessing the effects of chronic muroleptics, thus allowing comparison of the present moults with previous work. Female rats have been for practical reasons, including the fact that fendes do not gain weight at the same rate as males, mich allows for a more consistent dose regimen when using continuous subcutaneous HAL. This less ponounced weight increase also means that the numof of changes in tube apparatus is less with female thn with male animals. Finally, some evidence sugsts that the incidence of human TD is more prevamot in females than in males (Kane and Smith 1982). Animals in the present study were tested in a Plexidas tube for video-measured changes in oral movements. This test environment has been utilized in a mber of laboratories for assessing neurolepticduced changes in oral movements due to the ability b accurately measure detailed oral activity (Glenthoj ه d. 1990; Gunne et al. 1986; See and Ellison 1990a, 1906). However, it has been demonstrated that reobtained with this test apparatus differ in some opects from results obtained when rats are moniwed in an open cage environment (See and Ellison 900; Waddington 1990). For example, Levy et al. 1980) demonstrated an artifact that may be present then measuring oral movements of tranquilized mimals in an open cage but not in a tube apparatus. Thus, it is important to consider test environment when comparing results of different studies assessing dronic neuroleptic effects on oral movements.
The present results obtained from microdialysis sampling support our previous finding of increased DA turnover during continuous, chronic HAL administration (See 1991). The increases in DOPAC and HVA are not accompanied by an increase in basal DA, although a non-significant increase in DA levels was seen in both the present study and in previous experiments (See 1991; See et al. 1992). Based on recent microdialysis experiments (Camp and Robinson 1992), it has been suggested that changes in DOPAC are actually a better indicator of striatal dopaminergic integrity than DA itself. The increase in DA turnover does not appear to generalize to all monoamines, in that we found no increases in 5-HIAA levels in the present study or in previous experiments. It is also apparent that this phenomenon is late in onset, because we have failed to see increased basal DA metabolite concentrations after subchronic HAL administration of 3 weeks duration (See and Murray 1992), a finding in agreement with other laboratories utilizing microdialysis in subchronic HAL experiments (Hernandez and Hoebel 1989; Ichikawa and Meltzer 1990). However, the present study indicates that the increase in basal DA turnover during chronic HAL does not persist following withdrawal from the drug, at which point no differences in basal extracellular concentrations were seen between groups.

It has been consistently shown that oral dyskinesias produced by chronic neuroleptics can persist well after withdrawal of the offending drug in both animals (Gunne and Barany 1976; See and Ellison 1990a; Waddington 1990) and humans (Casey 1987). Although the neuroleptic-induced increase in DA turnover shows a late-onset pattern, increased DA metabolism does not persist following drug withdrawal. Thus, it would appear that although increased basal DA metabolism may be somehow related to the development of lateonset motor side effects, it does not follow the pattern predicted of persisting dyskinesia following drug withdrawal. One possibility as to the significance of increased DA metabolism during chronic HAL administration is that it may be associated with oxidative damage to striatal neurons, an effect that may be regionally specific to striatal regions mediating orofacial control (Seeman 1988). A widening number of studies have implicated the possibility of oxygen radical damage in neurodegenerative disorders, including TD (Cadet et al. 1986; Lohr 1991). Because oxidative metabolism constitutes a major source of free radical generation (Graham 1978; Cohen 1984), neuroleptics may produce neurotoxic effects that only develop with prolonged exposure (Nielsen and Lyon 1978; Jeste et al. 1992). Support for a relationship between DA turnover and oxidative activity comes from recent data demonstrating that rats fed a vitamin E-deficient diet show increased DA turnover in the cortex (Castano et 
al. 1992). A second possibility regarding the signifcance of increased DA turnover comes from experiments that have demonstrated the production of a toxic pyridinium metabolite of $\mathrm{HAL}\left(\mathrm{HPP}^{+}\right)$after $\mathrm{HAL}$ administration in rats (Subramanyam et al. 1990) and humans (Subramanyam et al. 1991). The increased DA turnover seen during chronic HAL treatment may be an indicator of increased oxidative biotransformation of $\mathrm{HAL}$ to $\mathrm{HPP}^{+}$leading to long-term neurotoxic damage in the striatum.

Direct infusion of AMP has been demonstrated to potently increase extracellular DA using microdialysis, presumably through its activation of cytosolic DA release (Nomikos et al. 1990). In the present study, a concentration of AMP that produces a highly signifcant increase in DA release did not reveal any signifcant differences between the chronic HAL-treated animals and control animals. It would thus appear that although basal DA turnover is increased by chronic $\mathrm{HAL}$, available pools of cytosolic DA are not differentially affected by a releasing agent. Because repeated neuroleptic exposure has been found to produce DA autoreceptor supersensitivity (Booth et al. 1991; Ichikawa and Meltzer 1990), one might expect that the HAL-treated animals would show an attenuated release of DA following AMP application due to negative feedback on presynaptic terminals. The present results indicate a trend in the opposite direction, that is, greater AMP-induced release in the HAL-treated animals. This may indicate greater availability of presynaptic DA in the HAL-treated animals or altered responsivity to the release-enhancing properties of AMP, either of which would counteract DA autoreceptor supersensitivity. Utilization of other drugs that affect presynaptic DA terminal function may further elucidate possible chronic HAL-induced effects on DA release.

Chronic administration of neuroleptics leads to a variety of neurochemical changes not apparent after acute or short-term treatment. The present study confirms the finding that increased basal DA turnover is a late-onset phenomenon of chronic neuroleptic administration that may play a role in the development of late-onset dyskinesias. However, because this increased DA metabolism is apparently not a lasting effect, it should be considered a possible indicator of the development, but not the persistence, of neuroleptic-induced dyskinesia.

\section{ACKNOWLEDGMENTS}

This research was supported by U.S. Public Health Service Grant DE09678 from the National Institutes of Health. Special thanks to Mary Ann Chapman and Cathy Murray for technical assistance and Gaylord Ellison and Mark Klitenick for helpful comments regarding the manuscript.

\section{REFERENCES}

Booth, RG, Baldessarini RJ, Campbell A (1991): Inhibitiond dopamine synthesis in rat striatal minces: Evidenced dopamine autoreceptor supersensitivity to $S(+)-$ but not $\mathrm{R}(-)-\mathrm{N}-\boldsymbol{n}$-propylnorapomorphine after pretreat. ment with fluphenazine. Biochem Pharmacol 41:20402043

Cadet JL, Lohr JB, Jeste DV (1986): Free radicals and tardive dyskinesia. Trends Neurosci 9:107-108

Caligiuri MP, Jeste DV, Harris MJ (1989): Instrumental af sessment of lingual motor instability in tardive dyskine sia. Neuropsychopharmacology 2:309-312

Camp DM, Robinson TE (1992): On the use of multipleprobe insertions at the same site for repeated intracerebra microdialysis experiments in the nigrostriatal dopamine system of rats. J Neurochem 58:1076-1715

Casey DE (1987): Tardive dyskinesia. In Meltzer HY (ed) Psychopharmacology: The Third Generation of Proo. ress. New York, Raven, pp 1411-1420

Castano A, Venero JL, Cano J, Machado A (1992): Changes in the turnover of monoamines in prefrontal cortex $d$ rats fed on vitamin $E$ deficient diet. J Neurochem 58: 1889-1895

Cohen G (1984): Oxy-radical toxicity in catecholamine netrons. Neurotoxicology 5:77-82

Di Paolo T, Falardeau P, Morissette M (1988): Striatal D.2 dopamine agonist binding sites fluctuate during therd estrous cycle. Life Sci 43:665-672

Ellison GD, See RE (1989): Rats administered chronic netroleptics develop oral movements which are similar in form to those in humans with tardive dyskinesia. Psy. chopharmacology 98:564-566

Ellison GD, Liminga U (1991): SK\&F 38393 or pilocarpine ir jected into the ventrolateral striatum elicit TD-like but not primed dystonia-like oral movements in rats at ministered chronic haloperidol. Soc Neurosci Abstr 17: 195

Ellison G, See RE (1991): A computerized methodology to the study of neuroleptic-induced oral dyskinesias. In Boulton A, Baker G, Martin-Iverson MT (eds), Nerromethods, Vol. 18: Animal Models in Psychiatry $L$ New York, Humana Press, pp 363-398

Ellison GD, Johansson P, Levin ED, See RE, Gunne W (1988): Chronic neuroleptics alter the effects on ord movements of the D1 agonist SK\&F 38393 and the D\& agonist LY171555. Psychopharmacology 96:253-257

Gerlach J, Casey DE (1988): Tardive dyskinesia. Acta P $P_{\pi}$ chiatr Scand 77:369-378

Glassman RB, Glassman HN (1980): Oral dyskinesia in brim damaged rats withdrawn from a neuroleptic: Implia tion for models of tardive dyskinesia. Psychopharm cology 69:19-25

Glenthoj B, Hemmingsen R, Allerup B, Bolwig TG (199. Intermittent versus continuous neuroleptic treatmenti a rat model. Eur J Pharmacol 190:275-286

Graham DG (1978): Oxidative pathways for catecholamine in the genesis of neuromelanin and cytotoxic quinones Mol Pharmacol 14:633-643

Gunne LM, Barany S (1976): Haloperidol-induced tardin 
dyskinesia in monkeys. Psychopharmacology 50: 237240

Coune LM, Growdon J, Glaeser B (1982): Oral dyskinesia in rats following brain lesions and neuroleptic drug administration. Psychopharmacology 77:134-139

Conne LM, Andersson U, Bondesson U, Johansson P (1986): Spontaneous chewing movements in rats during acute and chronic antipsychotic drug administration. Pharmacol Biochem Behav 25:897-901

Hemandez L, Hoebel BG (1989): Haloperidol given chronically decreases basal dopamine in the prefrontal cortex more than the striatum or nucleus accumbens as simultaneously measured by microdialysis. Brain Res Bull 22:763-769

Howa J, Meltzer HY (1990): Apomorphine does not reverse reduced basal dopamine release in rat striatum and nucleus accumbens after chronic haloperidol. Brain Res 507:138-142

Lte DV, Lohr JB, Manley M (1992): Study of neuropathological changes in the striatum following 4, 8, and 12 months of treatment with fluphenazine in rats. Psychopharmacology 106:154-160

Hensson P, Levin E, Gunne L, Ellison G (1987): Opposite effects of a D1 and D2 agonist on oral movements in rats. Eur J Pharmacol 134:83-88

Une JM, Smith JM (1982): Tardive dyskinesia: Prevalence and risk factors, 1959 to 1979. Arch Gen Psychiatry 39:473-481

Lnesque D, Gagnon S, Di Paolo T (1989): Striatal D1 dopamine receptor density fluctuates during the rat estrous sycle. Neurosci Lett 98:345-350

I $\sin$ ED, See RE, South D (1989): Effects of dopamine D1 and $\mathrm{D} 2$ receptor antagonists on oral activity in rats. Pharmacol Biochem Behav 34:43-48

In AD, See RE, Levin ED, Ellison GD (1987): Neurolepticinduced oral movements in rats: Methodological issues. Life Sci 41:1499-1506

Lots IB (1991): Oxygen radicals and neuropsychiatric illness. Arch Gen Psychiatry 48:1097-1106

Lats JB, Caligiuri MP (1992): Quantitative Instrumental measurement of tardive dyskinesia: A review. Neuropsychopharmacology 6:231-239

Hersden CD, Jenner P (1980): The pathophysiological basis of extrapyramidal movement disorders. Psychol Med 10:55-71

Katsen EB, Lyon M (1978): Evidence for cell loss in corpus striatum after long-term treatment with a neuroleptic drug (flupenthixol) in rats. Psychopharmacology 59: 85-89

Nhikswa T, Tanaka M, Koga I, Uchida Y (1985): Biphasic and long-lasting effect of ceruletide on tardive dyskinesia. Psychopharmacology 86:43-44

Momikos GG, Damsma G, Wenkstern D, Fibiger HC (1990): In vivo characterization of locally applied dopamine uptake inhibitors by striatal microdialysis. Synapse 6:106-112

rainos G Watson C (1986): The Rat Brain in Stereotaxic Coordinates, 2nd ed. San Diego, Academic Press
Robinson TW, Whishaw IQ (1988): Normalization of extracellular dopamine in striatum following recovery from a partial unilateral 6-OHDA lesion of the substantia nigra: A microdialysis study in freely moving rats. Brain Res 450:209-224

Rosengarten H, Schweitzer JW, Friedhoff AJ (1983): Induction of oral dyskinesias in naive rats by $\mathrm{D} 1$ stimulation. Life Sci 33:2479-2482

Rupniak NMJ, Tye SJ, Steventon MJ, Boyce S, Iversen SD (1990): Spontaneous orofacial dyskinesias in a captive cynomolgus monkey: Implications for tardive dyskinesia. Move Dis 5:314-318

See RE (1991): Striatal dopamine metabolism increases during long-term haloperidol administration in rats but shows tolerance to acute challenge with raclopride. Neurosci Lett 129:265-268

See RE, Ellison G (1990a): Intermittent and continuous haloperidol regimens produce different types of oral dyskinesias in rats. Psychopharmacology 100:404-412

See RE, Ellison G (1990b): Comparison of chronic administration of haloperidol and the atypical neuroleptics, clozapine and raclopride, in an animal model of tardive dyskinesia. Eur J Pharmacol 181:175-186

See RE, Murray CE (1992): Changes in striatal dopamine release and metabolism during and after subchronic haloperidol administration in rats. Neurosci Lett 142: 100-104

See RE, Levin ED, Ellison GD (1988): Characteristics of oral movements in rats during and after chronic haloperidol and fluphenazine administration. Psychopharmacology 94:421-427

See RE, Chapman MA, Murray CE, Aravagiri M (1992): Regional differences in chronic neuroleptic effects on extracellular dopamine activity. Brain Res Bull 29:473-478

Seeman P (1988): Tardive dyskinesia, dopamine receptors, and neuroleptic damage to cell membranes. J Clin Psychopharmacol 8:3S-9S

Stoessl AJ, Dourish CT, Iversen SD (1989): Chronic neuroleptic-induced mouth movements in the rat: Suppression by CCK and selective dopamine D1 and D2 receptor antagonists. Psychopharmacology 98:372-379

Subramanyam B, Rollema H, Woolf T, Castagnoli N (1990): Identification of a potentially neurotoxic pyridinium metabolite of haloperidol in rats. Biochem Biophys Res Commun 166:238-244

Subramanyam B, Pond SM, Eyles DW, Whiteford HA, Fouda HG, Castagnoli N (1991): Identification of potentially neurotoxic pyridinium metabolite in the urine of schizophrenic patients treated with haloperidol. Biochem Biophys Res Commun 181:573-578

Waddington JL (1990): Spontaneous orofacial movements induced in rodents by very long-term neuroleptic drug administration: Phenomenology, pathophysiology and putative relationship to tardive dyskinesia. Psychopharmacology 101:431-447

Wirshing WC, Friedenberg DL, Cummings JL, Bartzokis G (1989): Effects of anticholinergic agents on patients with tardive dyskinesia and concomitant drug-induced parkinsonism. J Clin Psychopharmacol 9:407-411 